\title{
Uji Antagonis Trichoderma sp dan Gliocladium sp terhadap Fusarium Penyebab Penyakit Layu pada Beberapa Jenis Tanaman Pisang di Kebun Raya Purwodadi secara in-vitro
}

\author{
In vitro Antagonism Test of Trichoderma sp. and Gliocladium sp. on Fusarium Causing \\ Wilt Disease on Various Banana Plants at Purwodadi Botanical Garden \\ ${ }^{1}$ Suharjono, ${ }^{1}$ Tri Handayani Kurniati, ${ }^{2}$ Soejono dan ${ }^{1}$ Susanti Dewi \\ ${ }^{1}$ Jurusan Biologi Fakultas MIPA Universitas Brawijaya, Malang 65145, e-mail : calistus@ brawijaya.ac.id \\ ${ }^{2}$ Kebun Raya Purwodadi, Pasuruan
}

\begin{abstract}
Purwodadi Botanical Garden has more than one hundred collection of cultivated bananas. The major problem in keeping their existency is the occuring of Fusarium wilt disease which was commonly controlled by pesticide or eradication to terminate the infectious cycles. Trichoderma and Gliocladium were frequently used as antagonist fungus in controlling the Fusarium wilt disease in kenaf, tomato or the other plants. So, this study aims was to know the potency of Trichoderma and Gliocladium on Fusarium growth inhibition. The experimental design was done by Randomized Complete Design Factorial using three factors i.e. antagonist fungus, Fusarium and growth distance. The level of retardation was measured by the growth distance of Fusarium that interacted to antagonist fungus and data analysis were conducted by Analysis of Variance (ANOVA). The results showed that Trichoderma has higher inhibition than Gliocladium and the highest inhibition occurred at $1 \mathrm{~cm}$ distance of inoculum which was performed on Fusarium 4 (77.78\%). There was not any significant differencies between Fusarium 1 with Trichoderma $(73.55 \%)$ and Fusarium 2 with Gliocladium $(73.33 \%)$. At $2 \mathrm{~cm}$ distance, the highest inhibition occurred in Fusarium 3 by Trichoderma $(\mathbf{7 2 . 7 1 \% )}$, which was not significantly different with Fusarium 1, 2 and 4 . While at $3 \mathrm{~cm}$ distance, the highest inhibition on Fusarium 4 by Trichoderma was $51.11 \%$ and not significantly different from Fusarium 1, 2 and 3.
\end{abstract}

Key word: Fusarium wilt disease, Trichoderma, Gliocladium, antagonist fungus

Diterima: 23 Maret 2003, disetujui: 15 Juli 2003

\section{Pendahuluan}

Fusarium merupakan kapang patogen utama pada beberapa jenis tanaman komoditi, terutama Fusarium oxysporum Schlect f.sp. cubense yang menyebabkan penyakit layu pada tanaman pisang (Satuhu dan Supriyadi, 1993). Penyakit layu Fusarium pertama kali ditemukan di Panama pada akhir tahun 1890 dan penyebarannya sangat luas termasuk di Indonesia. Penyakit tersebut juga banyak menyerang tanaman pisang di Kebun Raya Purwodadi yang sekarang belum ditangani secara serius. Sama dengan penanganan di negara lain, untuk memberantas Fusarium di Indonesia dilakukan dengan pemberian pestisida. Sampai sekarang pestisida belum mampu membasmi tuntas patogen tanaman pisang tersebut, sehingga pembasmian harus dilakukan dengan cara pemusnahan atau eradikasi untuk memutuskan siklus penularan Fusarium terhadap tanaman (Anonymous, 1995). Pengendalian patogen menggunakan pestisida yang berlebihan juga dapat menimbulkan resistensi patogen serta pencemaran lingkungan, sehingga perlu 
dikembangkan suatu cara pengendalian yang mampu menekan agen patogen tetapi hanya mempunyai pengaruh samping yang rendah (Anggraeni dan Suharti, 1996). Salah satu alternatif pengendalian Fusarium yang aman bagi organisme non-target dan rama lingkungan adalah pengendalian hayati, yang memanfaatkan mikroorganisme antagonis (Setiadi, 1987).

Trichoderma sp dan Gliocladium $\mathrm{sp}$ merupakan kapang yang efektif sebagai antagonis terhadap Fusarium patogen berbagai tanaman, dan keduanya juga merupakan antagonis potensial bagi Fusarium oxysporum Slecht (Domsch et al., 1972). Namun demikian belum diketahui berapa banyak jenis (isolat) Fusarium yang menyerang berbagai varietas tanaman pisang di Kebun Raya Purwodadi, serta bagaimana pengaruh penghambatan Trichoderma dan Gliocladium terhadap Fusarium patogen tersebut. Oleh karena itu penelitian ini bertujuan untuk mempelajari daya antagonis Trichoderma dan Gliocladium terhadap beberapa isolat Fusarium patoge tanaman pisang di Kebun Raya Purwodadi.

\section{Metode Penelitian}

\section{Isolasi Jamur Patogen}

Tanaman pisang yang menunjukkan gejala sakit ditebang, dan diambil bagian dalam batangnya kemudian dipotong-potong dan dimasukkan ke dalam kantong plastik. Sampel diiris secara aseptis dengan ketebalan $\pm 2 \mathrm{~mm}$, dan luasnya $0,5 \mathrm{~cm}^{2}$. Irisan sampel direndam dalam klorox $3 \%$ selama 1 menit, dicuci dengan aquades steril sebanyak 3 kali, lalu dikulturkan dalam media PDA (potato dextrose agar) yang mengandung Streptomisin 50 $\mathrm{mg} / \mathrm{L}$. Inkubasi dilakukan pada suhu $30^{\circ} \mathrm{C}$ selama selama 4 hari, kemudian kapang yang tumbuh diisolasi.

\section{Pembuatan Isolat Monospora}

Tiap isolat Fusarium, Trichoderma dan Gliocladium yang telah diisolasi, diinokulasi dalam media PDA miring dan diinkubasi selama 6 hari, pada suhu $30^{\circ} \mathrm{C}$.
Jika isolat jamur telah membentuk spora, ditambah aquades steril kemudian dikocok. Spora yang tersuspensi dalam aquades diambil dengan oose dan digoreskan pada permukaan media PDA. Biakan diinkubasi selama 10-18 jam, pada suhu $30^{\circ} \mathrm{C}$ dan kemudian diamati dengan mikroskop. Satu spora yang berkecambah dan terpisah dicuplik, kemudian dipindahkan ke media PDA baru dalam cawan petri. Pencuplikan spora dilakukan sebanyak 4 kali untuk tiap isolat kapang, diinkubasi selama 5 hari, pada suhu $30^{\circ} \mathrm{C}$. Bila koloni kapang sudah tumbuh dan tampak jelas morfologinya hanya satu jenis kapang; maka dipindahkan satu koloni di antara keempat koloni yang tumbuh tersebut ke cawan petri lainnya dan diinkubasi pada suhu $30^{\circ} \mathrm{C}$. Kapang yang sudah murni kemudian dibuat preparat mikroskopis dengan pewarnaan lactophenol cotton blue untuk identifikasi lanjut.

\section{Interaksi Fusarium Patogen dengan Trichoderma dan Gliocladium}

Masing-masing jenis Fusarium, Trichoderma dan Gliocladium dibuat isolat monospora. Tiap isolat Fusarium dengan umur 24 jam diinteraksikan dengan Trichoderma atau Gliocladium. Jarak peletakan antar inokulum masing-masing $1 \mathrm{~cm}, 2 \mathrm{~cm}$ dan $3 \mathrm{~cm}$. Setiap perlakuan diulang 3 kali pada tiap jarak yang berbeda. Untuk mengukur penghambatan Trichoderma dan Gliocladium terhadap Fusarium diamati dari jarak pertumbuhan koloni Fusarium yang menjauhi dan yang mendekati koloni kapang antagonis. Persentase penghambatan dihitung dengan rumus menurut Yeh and Sinclaer, 1980 (cis Anggraini dan Suhartati, 1996).

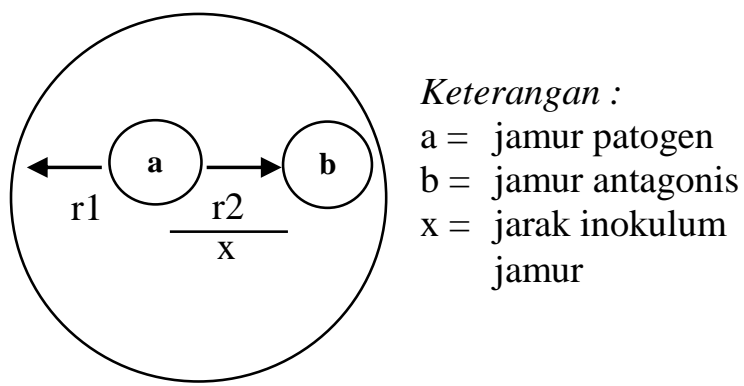

Rumus penghambatan: : $\underline{\mathbf{r 1}-\mathbf{r 2}} \times \mathbf{1 0 0 \%}$ 
r1 = jarak pertumbuhan koloni Fusarium yang menjauhi jamur antagonis

r2 $=$ jarak pertumbuhan koloni Fusarium yang mendekati jamur antagonis

\section{Rancangan Penelitian dan Analisis Data}

Rancangan penelitian yang digunakan adalah Rancangan Acak Lengkap Faktorial dengan tiga faktor yaitu jenis antagonis (Trichoderma dan Gliocladium), isolat Fusarium dan jarak inokulum $(1 \mathrm{~cm}, 2 \mathrm{~cm}$, dan $3 \mathrm{~cm}$ ). Data yang diperoleh dianalisis dengan ANOVA, dan apabila hasil beda nyata, dilanjutkan dengan uji Beda Nyata Jujur (BNJ) dengan $\alpha=5 \%$, menggunakan program SPSS for Windows Release 9.0.

\section{Hasil dan Pembahasan}

Hasil isolasi dan identifikasi, telah diperoleh empat isolat Fusarium pada tanaman pisang di Kebun Raya Purwodadi, yaitu Fusarium 1, 2, 3 dan 4, dengan ciri-ciri seperti pada Tabel 1. Berdasarkan hasil analisis ragam, didapatkan adanya perbedaan yang nyata antar jamur antagonis, antar isolat Fusarium dan antar jarak inokulum. Hasil penelitian juga menunjukkan terdapat interaksi antara jamur antagonis dengan isolat Fusarium, jamur antagonis dengan jarak inokulum, isolat Fusarium dengan jarak inokulum, tetapi tidak terdapat interaksi antara ketiganya terhadap parameter persentase penghambatan masingmasing.

Tabel 1. Hasil Pengamatan Ciri-ciri Isolat Fusarium

\begin{tabular}{|c|c|c|c|c|}
\hline Ciri - ciri & Fusarium 1 & Fusarium 2 & Fusarium 3 & Fusarium 4 \\
\hline \multicolumn{5}{|l|}{ a. Morfologi Koloni } \\
\hline - Warna pusat koloni & Coklat tua & $\begin{array}{l}\text { Putih } \\
\text { kehijauan }\end{array}$ & Putih & Putih \\
\hline - Warna tepi & Putih kecoklatan & Putih & Putih & Putih \\
\hline - Warna belakang pusat & Coklat & Hijau tua & Coklat & Coklat muda \\
\hline - Warna belakang tepi & Putih kecoklatan & Putih & $\begin{array}{l}\text { Putih } \\
\text { kecoklatan }\end{array}$ & Putih \\
\hline - Bentuk tepi & $\begin{array}{l}\text { Bundar, tepi } \\
\text { menyebar }\end{array}$ & Berbenang & Konsentris & Berbenang \\
\hline - Reaksi warna media & Putih keunguan & $\begin{array}{l}\text { Putih } \\
\text { kekuningan }\end{array}$ & Kuning & Kuning kecoklatan \\
\hline \multicolumn{5}{|l|}{ b. Mikroskopis } \\
\hline - Klamidospora & Tidak ada & Interkalar & Terminal & Terminal \\
\hline - Makrokonidia & $\begin{array}{l}\text { Panjang, kedua } \\
\text { ujung runcing, } \\
\text { empat sekat }\end{array}$ & $\begin{array}{l}\text { Agak pendek, } \\
\text { ujung tumpul, } \\
\text { tiga sekat }\end{array}$ & $\begin{array}{l}\text { Agak pendek, } \\
\text { ujung runcing, } \\
\text { satu sekat }\end{array}$ & $\begin{array}{l}\text { Panjang, ujung tumpul, } \\
\text { 3-4 sekat }\end{array}$ \\
\hline - Mikrokonidia & $\begin{array}{l}\text { Pendek, ujung } \\
\text { tumpul., dua sekat }\end{array}$ & $\begin{array}{l}\text { Pendek, ujung } \\
\text { tumpul, satu } \\
\text { sekat }\end{array}$ & $\begin{array}{l}\text { Pendek, ujung } \\
\text { tumpul, satu } \\
\text { sekat }\end{array}$ & $\begin{array}{l}\text { Pendek, ujung tumpul, } \\
1-2 \text { sekat }\end{array}$ \\
\hline - Patogen pada pisang & $\begin{array}{l}\text { Kluthuk Sukun, } \\
\text { Raja Talun }\end{array}$ & $\begin{array}{l}\text { Kluthuk } \\
\text { Sukun }\end{array}$ & Susu Gabuk & Prenthel \\
\hline
\end{tabular}

Hasil uji antagonis menunjukkan bahwa daya hambatan Trichoderma terhadap Fusarium dipengaruhi oleh perbedaan isolat Fusarium dan jarak antar inokulum (Gambar 1). Daya hambatan Trichoderma paling tinggi adalah terhadap Fusarium 4, dengan jarak inokulum $1 \mathrm{~cm}$ dengan persentase hambatan $77,78 \%$ yang relatif sama dengan Fusarium 3 dengan jarak inokulum $2 \mathrm{~cm}$ dan Fusarium 1 dengan jarak inokulum $1 \mathrm{~cm}$. Daya hambatan Trichoderma paling rendah terjadi pada Fusarium 1, dengan jarak inokulum $3 \mathrm{~cm}$ yaitu 
$47,43 \%$ yang tidak berbeda nyata dengan Fusarium 2 pada jarak inokulasi $3 \mathrm{~cm}$. Daya hambatan Trichoderma terhadap berbagai isolat Fusarium menunjukkan bahwa semakin jauh jarak antar inokulum, maka semakin kecil daya antagonisnya. Hal ini disebabkan senyawa yang dihasilkan oleh agen pengendali (Trichoderma) lebih cepat kontak terhadap Fusarium pada jarak inokulum yang lebih dekat.

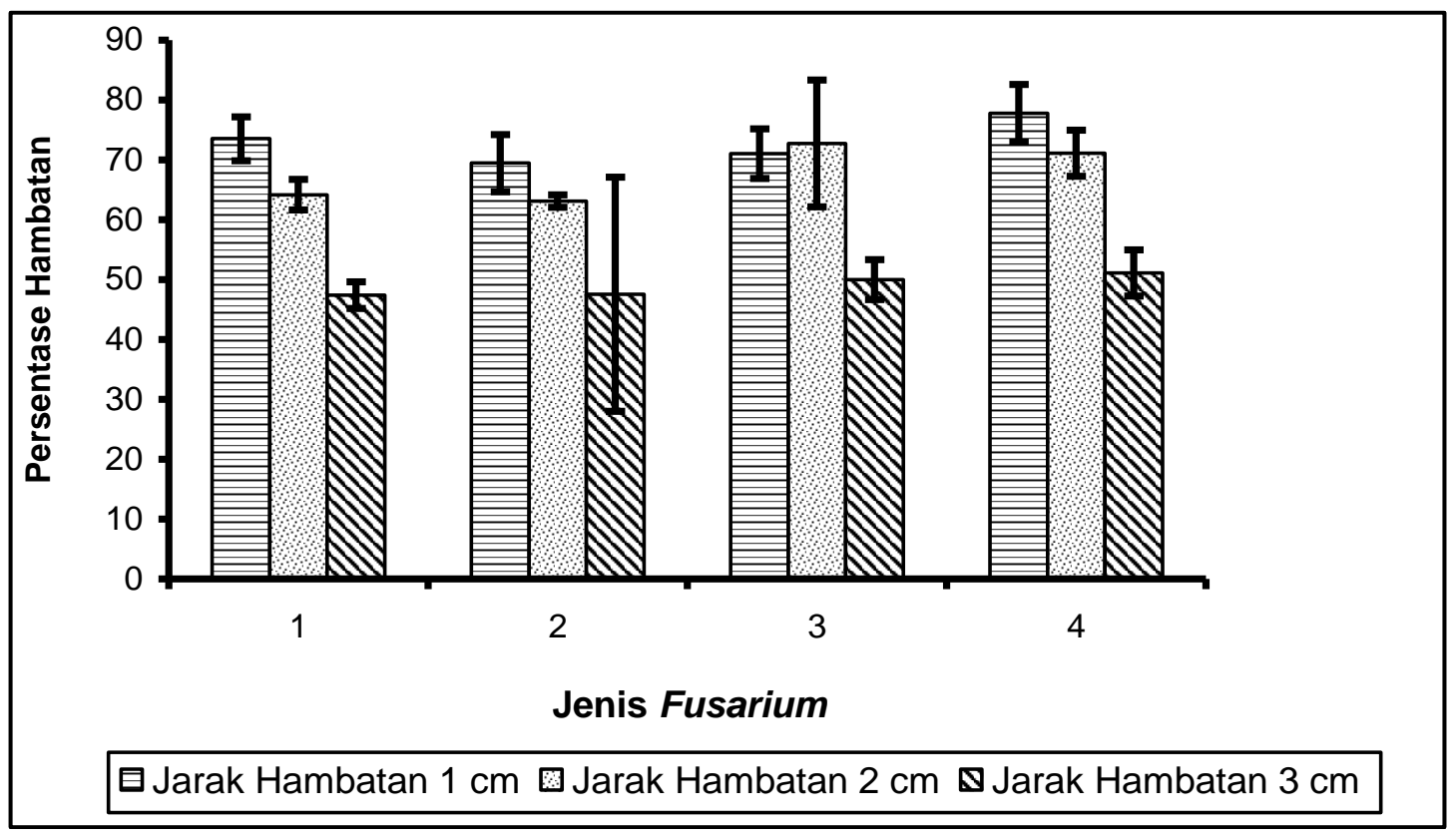

Gambar 1. Daya hambat Trichoderma terhadap Fusarium

Daya hambatan tertinggi oleh Gliocladium terjadi pada Fusarium 2, dengan jarak inokulasi 1 $\mathrm{cm}$ sebesar $73,33 \%$ dan terendah terhadap Fusarium 1 pada jarak inokulasi $3 \mathrm{~cm}(1,85 \%)$. Hasil tersebut juga menunjukkan bahwa pengaruh penghambatan Gliocladium terhadap Fusarium secara nyata dipengaruhi oleh perbedaan jenis isolat dan jarak antar inokulum. Daya hambatan baik oleh Trichoderma dan Gliocladium terhadap keempat jenis isolat Fusarium menunjukkan bahwa semakin jauh jarak antar inokulum, maka semakin kecil daya antagonisnya. Hal ini menunjukkan bahwa daya hambatan tersebut lebih efektif bila jarak antar inokulum cukup dekat. Semakin dekat jarak antar inokulum maka semakin cepat terjadi kontak antara antibiotik yang dihasilkan agen terhadap koloni kapang yang dihambat.

Pada jarak inokulum $1 \mathrm{~cm}$, Trichoderma menghambat Fusarium relatif lebih besar dibandingkan Gliocladium. Hal tersebut terjadi karena laju pertumbuhan Trichoderma lebih cepat bila dibandingkan dengan Gliocladium, sehingga lebih cepat terjadi kontak untuk menghambat Fusarium. Interaksi jamur antagonis dengan Fusarium pada jarak $2 \mathrm{~cm}$, menunjukkan bahwa pada jarak ini Trichoderma menghambat keempat isolat Fusarium dengan hambatan yang lebih besar dibandingkan dengan hambatan yang disebabkan oleh Gliocladium.

Hambatan terkecil terjadi pada Fusarium 1 oleh Gliocladium karena pertumbuhan Gliocladium lebih lambat dibandingkan Trichoderma dan Fusarium. Hasil analisis interaksi jamur antagonis dengan Fusarium pada jarak $3 \mathrm{~cm}$ menunjukkan adanya kemiripan dengan hasil pada jarak $2 \mathrm{~cm}$ yaitu Trichoderma menghasilkan hambatan yang lebih besar dibandingkan Gliocladium untuk keempat isolat Fusarium. Hambatan Trichoderma terhadap keempat isolat Fusarium tidak berbeda nyata, sedangkan hambatan oleh Gliocladium berbeda nyata pada setiap isolat Fusarium. Hambatan terkecil oleh Gliocladium terjadi pada Fusarium 1 sebesar 1,85\%, sedangkan hambatan terbesar diperoleh pada Fusarium 3 sebesar 16,67\% (Gambar 2). 


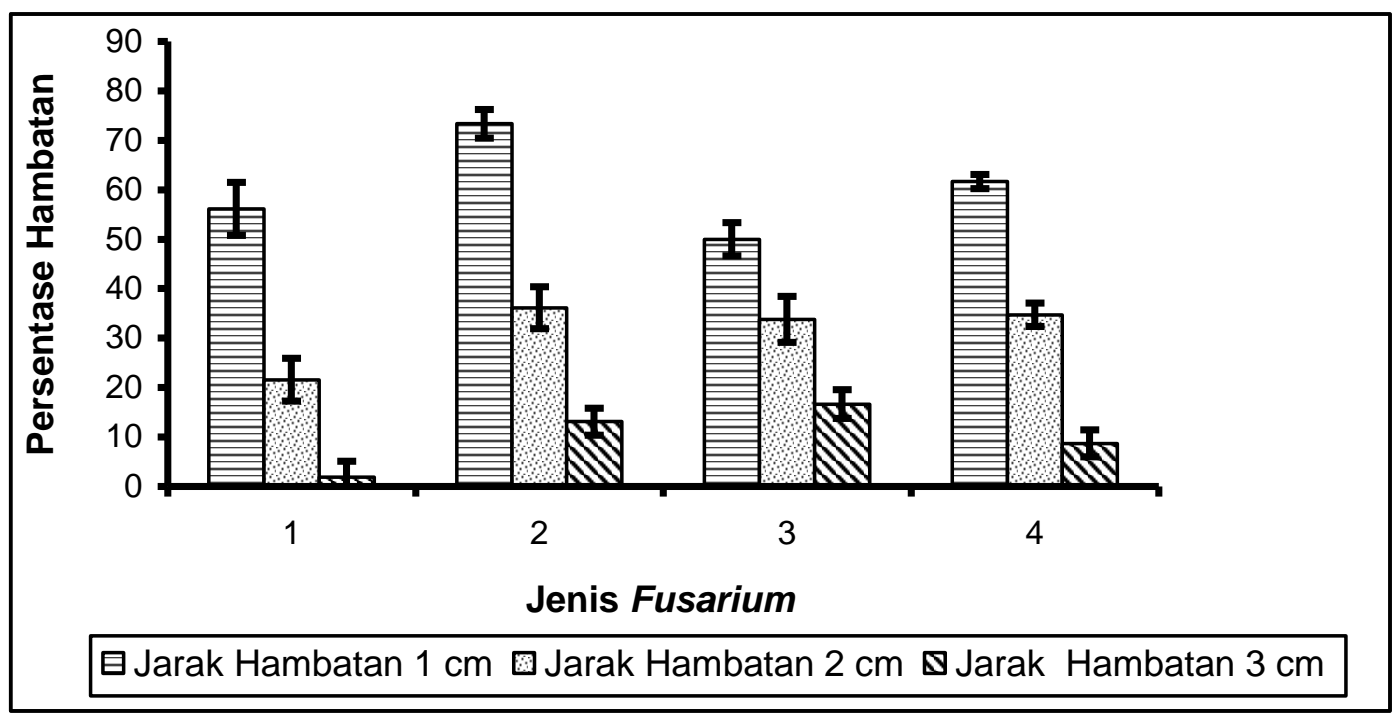

Gambar 2. Daya hambat Gliocladium terhadap Fusarium

Berdasarkan variasi jarak inokulum maupun jenis Fusarium, Trichoderma menghasilkan hambatan yang lebih besar terhadap Fusarium dibandingkan Gliocladium karena kecepatan pertumbuhan koloninya lebih tinggi daripada Gliocladium maupun Fusarium. Menurut Domsch et al. (1972) koloni Trichoderma mempunyai diameter 4,5$7,5 \mathrm{~cm}$ dalam waktu 5 hari, Gliocladium berdiameter 2,4 - 3,5 cm dalam waktu sepuluh hari, sedangkan Fusarium berdiameter 4,5-6,5 $\mathrm{cm}$ dalam waktu 4 hari. Menurut Domsch dan Gans (1972) dalam waktu 5 hari diameter koloni Trichoderma viridae mampu mencapai 90 mm, sedangkan menurut Nelson (1981) diameter Fusarium oxysporum akan mencapai $75 \mathrm{~mm}$ dalam waktu 7 hari. Jadi Trichoderma mempunyai kecepatan pertumbuhan yang paling tinggi di antara ketiga genus tersebut dan ini merupakan salah satu kelebihan Trichoderma untuk dapat menghambat pertumbuhan Fusarium. Abadi (1987) menyatakan bahwa kemampuan Trichoderma viridae untuk menghambat pertumbuhan Fusarium sangat baik, karena kapang saprofit ini memiliki pertumbuhan yang sangat cepat sehingga mampu menutupi seluruh koloni Fusarium yang diinteraksikan serta miselium
Trichoderma dapat menyebabkan lisisnya miselium Fusarium yang kontak dengannya.

Gliocladium memiliki kelebihan yaitu lebih tahan terhadap pengaruh lingkungan yang ekstrim dibandingkan Trichoderma dan Fusarium. Di samping itu Gliocladium memiliki keistimewaan tersendiri yaitu penyebaran sporanya sangat mudah dan cepat tumbuh sehingga koloninya akan lebih banyak dibandingkan koloni Fusarium. Menurut Sinaga (1990), pemilihan Gliocladium sebagai agen biokontrol karena spora istirahatnya tahan terhadap lingkungan ekstrem, menghasilkan senyawa toksik yang dapat mematikan atau menghancurkan sel organisme lain (patogen) dan sifatnya yang saprofit (hidup dari sisa-sisa bahan organik) sehingga perbanyakannya lebih mudah.

Waktu yang diperlukan Trichoderma dan Gliocladium untuk menghambat keempat isolat Fusarium berbeda pada jarak yang berbeda. Trichoderma pada jarak inokulum 1 $\mathrm{cm}$ dan $2 \mathrm{~cm}$ memerlukan waktu sekitar 24 jam, sedangkan pada jarak inokulum $3 \mathrm{~cm}$ memerlukan waktu sekitar 48 jam untuk menghambat Fusarium.

Gliocladium pada jarak inokulum $1 \mathrm{~cm}$ memerlukan waktu sekitar 48 jam sedangkan 
pada jarak $2 \mathrm{~cm}$ dan $3 \mathrm{~cm}$ memerlukan waktu sekitar 72 jam untuk menghambat Fusarium. Perbedaan waktu penghambatan yang terjadi antara Trichoderma dan Gliocladium terjadi karena pertumbuhan koloni Trichoderma lebih cepat dibandingkan dengan koloni Gliocladium.

Menurut Papavizas (1985) adanya penghambatan terhadap Fusarium ini karena Trichoderma mempunyai senyawa toksik trichodermin yang merupakan antibiotik sesquiterpene yang aktif terhadap jamur. Gliocladium selain menghasilkan toksin, juga menghasilkan antibiotik dan enzim-enzim seperti eksoglukanase, endoglukanase, selobiase dan khitinase. Adanya kandungan senyawa-senyawa tersebut pada Trichoderma dan Gliocladium, menyebabkan kedua kapang antagonis ini mampu mematikan Fusarium dengan melisiskan miseliumnya.

\section{Kesimpulan}

Trichoderma dan Gliocladium merupakan jamur antagonis yang mampu menghambat pertumbuhan Fusarium. Berdasarkan besarnya hambatan yang dihasilkan dan waktu (kecepatan) terjadinya penghambatan, Trichoderma lebih efektif untuk menghambat Fusarium dibandingkan dengan Gliocladium.

Variasi jarak inokulum mempengaruhi besarnya penghambatan yang dihasilkan. Jarak inokulum jamur $1 \mathrm{~cm}$ untuk Trichoderma atau Gliocladium, merupakan jarak yang paling efektif untuk menghambat Fusarium.

\section{Saran}

Penelitian ini merupakan studi awal uji antagonis Trichoderma dan Gliocladium terhadap Fusarium penyebab penyakit layu pada tanaman pisang pada skala laboratorium. Oleh karena itu perlu dilakukan penelitian lebih lanjut tentang potensi Trichoderma dan Gliocladium dalam menghambat Fusarium di lapangan.

\section{Daftar Pustaka}

Abadi, A.L., 1987. Biologi Ganoderma boninenese Pat. pada Kelapa Sawit (Alaesis guineensis Jacq) dan Pengaruh Mikroba Tanah Antagonistik Terhadap Pertumbuhannya. Tesis S-2, Fakultas Pasca Sarjana Institut Pertanian Bogor, Bogor.

Anggraeni, I. dan Suharti, M., 1996, Pengaruh Bahan Organik Terhadap Aktivitas Trichoderma sp. Dalam Pengendalian Fusarium sp. Secara In-vitro, Pusat Penelitian dan Pengembangan Hutan dan Konversi Alam, Bogor.

Anonymous, 1995. Cendawan dan Bakteri Ancaman Petani Pisang, Pusat Informasi Pertanian Trubus, Jakarta.

Domsch, K.H., Gams, W. and Anderson, T.H., 1972. Copendium of Soil Fungi volume 1, Academic Press, A Subsidiary of Harcourt Brace Jovanovich Publishers, London.

Nelson, P.E., 1981. Life Cycle and Epidemiology of Fusarium oxysporum, in Mace, M.E., Bell, A.A. and Beckman, C,H. (eds), Academic Press, A Subsidiary of Harcourt Brace Jovanovich Publishers, New York.

Papavizas, G.C., 1985. Trichoderma and Gliocladium: Biology, Ecology and Potensial for Biocontrol, Ann. Rev. Phytopathol. 23: 23-54.

Satuhu, S. dan Supriyadi, A., 1993. Pisang: Budidaya, Pengolahan dan Prospek Pasar, Penerbit Penebar Swadaya, Jakarta.

Setiadi, 1987. Bertanam Cabai, CV. Penebar Swadaya, Jakarta.

Sinaga, M., 1990. Cendawan vs Cendawan dalam Pengendalian Hayati, KOMPAS, Jakarta. 